\title{
Neonatal presentation of ventricular tachycardia and a Reye-like syndrome episode associated with disturbed mitochondrial energy metabolism
}

\author{
Fernando Scaglia*1, Angela E Scheuerle4,5, Jeffrey A Towbin 1,2, \\ Dawna L Armstrong ${ }^{3}$, Lawrence Sweetman ${ }^{6}$ and Lee-Jun C Wong7
}

\begin{abstract}
Address: ${ }^{1}$ Department of Molecular and Human Genetics, Baylor College of Medicine, Houston, TX, 77030, USA, ${ }^{2}$ Department of Pediatrics, Baylor College of Medicine, Houston, TX, 77030, USA, ${ }^{3}$ Department of Pathology, Baylor College of Medicine, Houston, TX, 77030, USA, ${ }^{4}$ Department of Genetics, Teratology and Ethics Consulting, Dallas, TX, USA, ${ }^{5}$ Texas Birth Defects Research Center, Dallas, TX, USA, ${ }^{6}$ Baylor Institute of Metabolic Disease, Dallas, TX, 75226, USA and 7 Institute for Molecular and Human Genetics, Georgetown University Medical Center, Washington DC, 20007, USA

Email: Fernando Scaglia* - fscaglia@bcm.tmc.edu; Angela E Scheuerle - Angela.Scheuerle@tdh.state.tx.us; Jeffrey A Towbin - jtowbin@bcm.tmc.edu; Dawna L Armstrong - dawnaa@bcm.tmc.edu; Lawrence Sweetman - larrys@BaylorHealth.edu; LeeJun C Wong - wonglj@georgetown.edu

* Corresponding author
\end{abstract}

This article is available from: http://www.biomedcentral.com/I47/-243I/2/12

(C) 2002 Scaglia et al; licensee BioMed Central Ltd. This is an Open Access article: verbatim copying and redistribution of this article are permitted in all media for any purpose, provided this notice is preserved along with the article's original URL.

\begin{abstract}
Background: Hyperammonemia, hypoglycemia, hepatopathy, and ventricular tachycardia are common presenting features of carnitine-acylcarnitine translocase deficiency (Mendelian Inheritance in Man database: $* 2 / 2138$ ), a mitochondrial fatty acid oxidation disorder with a lethal prognosis. These features have not been identified as the presenting features of mitochondrial cytopathy in the neonatal period.
\end{abstract}

Case presentation: We describe an atypical presentation of mitochondrial cytopathy in a 2 dayold neonate. She presented with a Reye-like syndrome episode, premature ventricular contractions and ventricular tachycardia. Initial laboratory evaluation exhibited a large amount of 3methylglutaconic acid on urine organic acid analysis, mild orotic aciduria and a nonspecific abnormal acylcarnitine profile. The evaluation for carnitine-acylcarnitine translocase deficiency and other fatty acid oxidation disorders was negative. The patient later developed a hypertrophic cardiomyopathy and continued to be affected by recurrent Reye-like syndrome episodes triggered by infections. A muscle biopsy exhibited signs of a mitochondrial cytopathy. During the course of her disease, her Reye-like syndrome episodes have subsided; however, cardiomyopathy has persisted along with fatigue and exercise intolerance.

Conclusions: This case illustrates that, in the neonatal period, hyperammonemia and ventricular tachycardia may be the presenting features of a lethal carnitine-acylcarnitine translocase deficiency or of a mitochondrial cytopathy, associated with a milder clinical course. This association broadens the spectrum of presenting phenotypes observed in patients with disturbed mitochondrial energy metabolism. Also, the presence of 3-methylglutaconic aciduria suggests mitochondrial dysfunction and mild orotic aciduria could potentially be used as a marker of mitochondrial disease. 


\section{Background}

Mitochondrial cytopathies are a heterogeneous group of disorders that can affect almost all organ systems reflecting ATP depletion. Neuromuscular disorders were the first to be studied, and direct evidence of mitochondrial DNA (mtDNA) abnormalities was demonstrated in $1988[1,2]$. However, only $6 \%$ of the patients suspected of having mitochondrial disorders have been found to have mtDNA point mutations or deletions [3]. Most pediatric mitochondrial disorders are caused by defects in nuclear genes and with an autosomal recessive inheritance [4]. This case of neonatal mitochondrial dysfunction presenting with hyperammonemia and ventricular tachycardia expands the clinical spectrum of these disorders.

\section{Case presentation}

We report the case of a 1 day-old neonate with unusual presenting features of a mitochondrial cytopathy and a unique clinical course. She was born at term after an uncomplicated pregnancy to healthy, unrelated parents of Northern European descent with a negative family history. On her first day of life, she was noted to be lethargic, and was feeding poorly. Persistent hypoglycemia, hypothermia and seizures precipitated her transfer to the neonatal intensive care unit. On physical exam she was found to be a non-dysmorphic, term female. Birth weight was 3515 grams ( $80^{\text {th }}$ centile), length was $48.6 \mathrm{~cm}$ (50 th $\mathrm{cen}$ tile) and head circumference was $35 \mathrm{~cm}\left(75^{\text {th }}\right.$ centile). Significant findings on her physical exam included a distended abdomen with hepatomegaly and hypotonia. Tests for bacterial and viral infections were ultimately negative. The patient was noted to have hypoglycemia (30 $\mathrm{mg} / \mathrm{dl}$ ) with a small amount of ketones in the urine. She had an elevated ammonia level of $357 \mu \mathrm{mol} / \mathrm{L}$ (normal range: 22-48), lactic acid of $10 \mathrm{mmol} / \mathrm{l}$ (normal range: $0.2-2)$, elevated transaminases with an alanine aminotransferase of $69 \mathrm{U} / \mathrm{L}$ (normal range: 10-25), an aspartate aminotransferase of $162 \mathrm{U} / \mathrm{L}$ (normal range: 15-50), and hypothermia with deteriorating neurological condition. She was subsequently treated with intravenous glucose. Sodium benzoate, sodium acetate, and arginine hydrochloride were administered intravenously to treat her hyperammonemia that eventually responded twentyfour hours after initiation of therapy. In view of her hyperammonemia, she was placed on a protein-restricted diet ( $2 \mathrm{~g} / \mathrm{kg} /$ day) at 3 days of age. Her neurologic status improved steadily after her hyperammonemia was controlled. Brain MRI was reportedly normal. Electroencephalogram demonstrated diffuse encephalopathy. Her initial presentation with hyperammonemia prompted a genetics consult. Plasma amino acid analysis showed an elevated alanine of $631 \mu \mathrm{mol} / \mathrm{L}$ (normal range: 141-343) with no other abnormalities. Measurement of carnitine levels showed no evidence of carnitine depletion. However tandem mass spectrometry of acylcarni- tines revealed a slightly elevated propionylcarnitine of 1.4 $\mu \mathrm{M}$ (normal range:0-0.4 $\mu \mathrm{M}$ ) that was not to the extent seen in organic acidemias. Quantitative analysis of urine organic acids by gas chromatography/mass spectrometry exhibited elevated levels of 3-methylglutaconic (3-MGC) acid of $121 \mathrm{mmol} / \mathrm{mol}$ of creatinine (normal range:0-8) and 3-methylglutaric (3-MGR) acid of $33 \mathrm{mmol} / \mathrm{mol}$ of creatinine (normal range:0-2) with a normal level of 3hydroxyisovaleric acid of $40 \mathrm{mmol} / \mathrm{mol}$ of creatinine (normal range:0-39) making the diagnosis of type I 3MGC aciduria less likely. Her urine orotic acid was mildly elevated at 81 nmoles orotic acid/mg creatinine (normal range: $<60$ nmoles orotic acid/mg creatinine).

At 4 days of age, she developed premature ventricular contractions that were immediately followed by sustained ventricular tachycardia that eventually responded to treatment with $\beta$-blockers. Initial work-up did not reveal any evidence of a cardiomyopathy. A skin biopsy was performed to rule out carnitine-acylcarnitine translocase deficiency and other fatty acid oxidation disorders. At 10 days of age, the proband was noted to have a heart murmur and an echocardiogram revealed at that time, hypertrophic cardiomyopathy with moderate left ventricular hypertrophy and a left ventricular shortening fraction of $30 \%$. Her special diet was discontinued prior to discharge since the results of plasma amino acids, urine organic acids, and urine orotic acid did not support the possible diagnoses of a primary urea cycle disorder or organic acidemia as the etiology of her hyperammonemia. Carnitine-acylcarnitine translocase deficiency or other type of fatty acid oxidation disorder was suspected because of her initial presentation. Once on full feeds, a trial off sodium benzoate, sodium phenylacetate, and arginine resulted in maintenance of her ammonium levels below $100 \mu \mathrm{mol} / \mathrm{L}$. The patient was discharged at sixteen days of age on full breast milk feeds, and a $\beta$-blocker.

Fibroblasts were incubated with palmitate labeled with deuterium and L-carnitine and fatty acid oxidation studies with an in vitro probe were conducted. Normal levels of labeled intermediates were observed from C16 to C4 without evidence for translocase deficiency or any other type of fatty acid oxidation disorder. At two months of age, she was mildly hypotonic on a follow up evaluation and the diagnosis of a possible mitochondrial cytopathy was suspected. Because of a suspicion of a possible mitochondrial disorder, the activities of pyruvate dehydrogenase, pyruvate carboxylase, and mitochondrial respiratory chain enzyme activities (complexes II-IV) were tested in fibroblasts with normal results. Ophthalmologic and audiologic evaluations were normal. Her urinary organic acid profile remained unchanged in the fasting and postprandial states. Over a period of four years, the patient was admitted several times for recurrent Reye-like syndrome epi- 
sodes triggered by viral illnesses and decreased oral intake. Though one of these episodes was associated with cardiac arrest at two years of age, she always responded well to treatment without apparent neurological sequelae. At 11 months, there was a concern about possible failure to thrive, nevertheless, her current growth and development at seven years of age have been adequate. The proband has developed a clinical course characterized by increasing tolerance to fasting and illness without further episodes of metabolic decompensation. At seven years of age, she has exhibited fatigue, exercise intolerance and palpitations as the main features of abnormal mitochondrial energy metabolism. No episodes of sustained ventricular tachycardia have been documented recently. Her cardiomyopathy has improved and the results of her last echocardiogram showed mild left ventricular hypertrophy and a left ventricular shortening fraction of 50\%.

\section{Methods \\ Muscle biopsy}

A muscle biopsy was performed at 30 months of age, during a hospitalization for a Reye-like syndrome episode, to further pursue the work-up of a mitochondrial disorder. Cryostat sections of flash frozen muscle were stained with hematoxylin and eosin, the modified Gomori trichrome stain, and for succinate dehydrogenase, cytochrome c oxidase activity, reduced nicotinamide adenine dinucleotide (NADH) dehydrogenase, and adenosine triphosphatase (ATPase) activities at pH 4.3 and 4.6. Muscle was also fixed in glutaraldehyde for electron microscopy.

\section{Respiratory chain enzyme analysis}

Respiratory chain enzymes were measured in 10\% homogenates using previously described methods as follows: NADH dehydrogenase [5], NADH cytochrome c reductase [5], succinate dehydrogenase [6], succinate cytochrome c reductase [6], cytochrome c oxidase [7], and citrate synthase [8]. Enzyme activities were expressed as $\mu \mathrm{mol} / \mathrm{min} / \mathrm{g}$ of wet weight tissue.

\section{MtDNA mutation analysis}

MtDNA from blood and skeletal muscle was extracted and analyzed for mtDNA point mutations, deletions or duplications by multiplex polymerase chain reaction-allele specific oligonucleotide (PCR/ASO) dot blot hybridization and Southern blot analysis. Quantitative evaluation of mtDNA content was performed in skeletal muscle by Southern blot and Real Time quantitative PCR analyses [9]. To look for unknown mtDNA mutations, the entire mitochondrial genome was screened by temporal temperature gel electrophoresis (TTGE) on mother/child pair, followed by sequencing of the DNA fragments that exhibited different banding patterns between mother and child.

\section{Results \\ Muscle biopsy}

Gomori trichrome stain revealed ragged red fibers (Figure 1). Electron microscopy showed concentric arrangements of cristae with rare dense bodies, excess glycogen and fat deposition, and focal rare Z-disc streaming (Figure 2).

\section{Enzyme studies}

The activity of the mitochondrial respiratory chain enzymes, although mostly below the normal mean, was within the normal range in skeletal muscle with moderate increase $(52 \%)$ in the activity of citrate synthase suggesting mitochondrial proliferation (Table 1).

\section{MtDNA mutation analysis by PCRIASO dot blot hybridiza- tion and Southern blot}

MtDNA common point mutations (MELAS A3243G and T3271C, MERRF A8344G and T8356C, NARP T8993G and T8993C, cardiomyopathy G8363A, and LHON G11778A, G3460A, T14484C, and G14459A), deletions, or duplications, were not detected in blood or skeletal muscle. A cardiomyopathy screen was negative for the 6 point mutations in mtDNA reported in patients with cardiomyopathy: A3243G, C3303T, A4269G, A4300G, G8363A and T9997C.

\section{Quantitative mtDNA analysis}

Quantitative evaluation of mtDNA content in patient's muscle specimen revealed no evidence of mtDNA depletion.

\section{TTGE and MtDNA sequencing}

A homoplasmic T3197C nucleotide substitution was detected in this patient's blood and muscle and it was also detected on the proband's mother and on two half siblings. Both mother and child were found to have two common polymorphisms in homoplasmic state, G185A and A73G. An obvious difference was found in the D-loop region where A189G was present in the proband in a near homoplasmic state and homoplasmic wild type A189 was present in the proband's mother. A novel germline variation, 568-573 insCCCCC, was present in both mother and the proband. Four mtDNA regions that did not exhibited any difference between mother and proband's mtDNA on TTGE analysis (nucleotide position 3085 to 3758, 4013 to 4508,8295 to 8600 , and 9827 to 10286 ) were sequenced. The results confirmed the presence of T3197C polymorphism in both mother and the proband. No other mutations in these regions, including the 6 point mutations reported in patients with cardiomyopathy as stated above, were detected. 

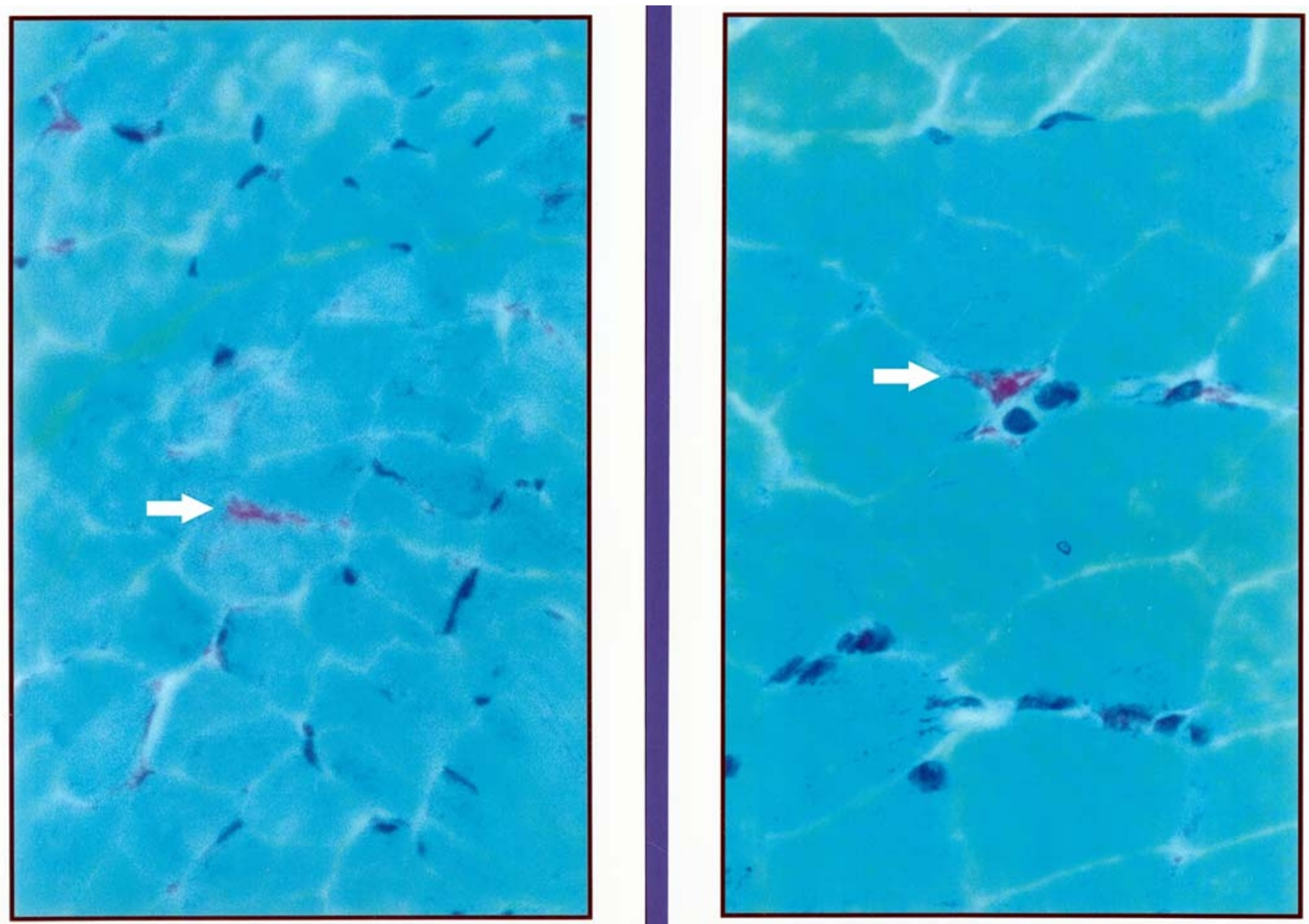

Figure I

Gomori trichrome stain of skeletal muscle. Gomori trichrome stain of skeletal muscle reveals ragged red fibers (arrow).

\section{Discussion}

\section{Reye-like syndrome episodes}

Reye syndrome, a disorder of unknown cause, is characterized by acute encephalopathy and fatty degeneration of the liver and it is usually characterized by a history of preceding viral illness or the use of aspirin during viral infections [10]. Many children with metabolic disorders present with Reye-like syndrome episodes, usually at a young age and/or with a positive past or family history suspicious for an inborn error of metabolism [11]. It has been reported as a presenting sign of type I 3-MGC aciduria and in a few cases of mitochondrial cytopathies in older children $[12,13]$. However in the neonatal period, a Reye-like episode is not a typical presenting feature of a mitochondrial cytopathy.

\section{Cardiac involvement in mitochondrial diseases}

Inborn errors of mitochondrial fatty acid oxidation should be considered in infants with conduction defects or ventricular tachycardia. In 24 children with inherited disorders of fatty acid oxidation, conduction defects or arrhythmias were the predominant presenting feature [14]. Arrhythmias in association with hepatomuscular symptoms and hyperammonemia have also been demonstrated in cases of carnitine-acylcarnitine translocase deficiency whose presenting features also include neonatal distress, convulsions, hypoglycemia, hypoketonemia, intermittent dicarboxylic aciduria, hypothermia, apnea, neurological deterioration, and hypocarnitinemia with grossly elevated acylcarnitines [15]. The accumulation of arrhythmogenic metabolites of fatty acids, such as long chain acylcarnitines, may be responsible for the observed lethal cardiac defects. Cardiac conduction disturbance has also been recognized in the mitochondrial cytopathy, Kearns-Sayre syndrome (Mendelian inheritance in Man database $* 530000$ ), characterized as progressive external ophthalmoplegia and retinopathy [16]. Clinical manifestations of cardiac disease occur in $57 \%$ of patients with 


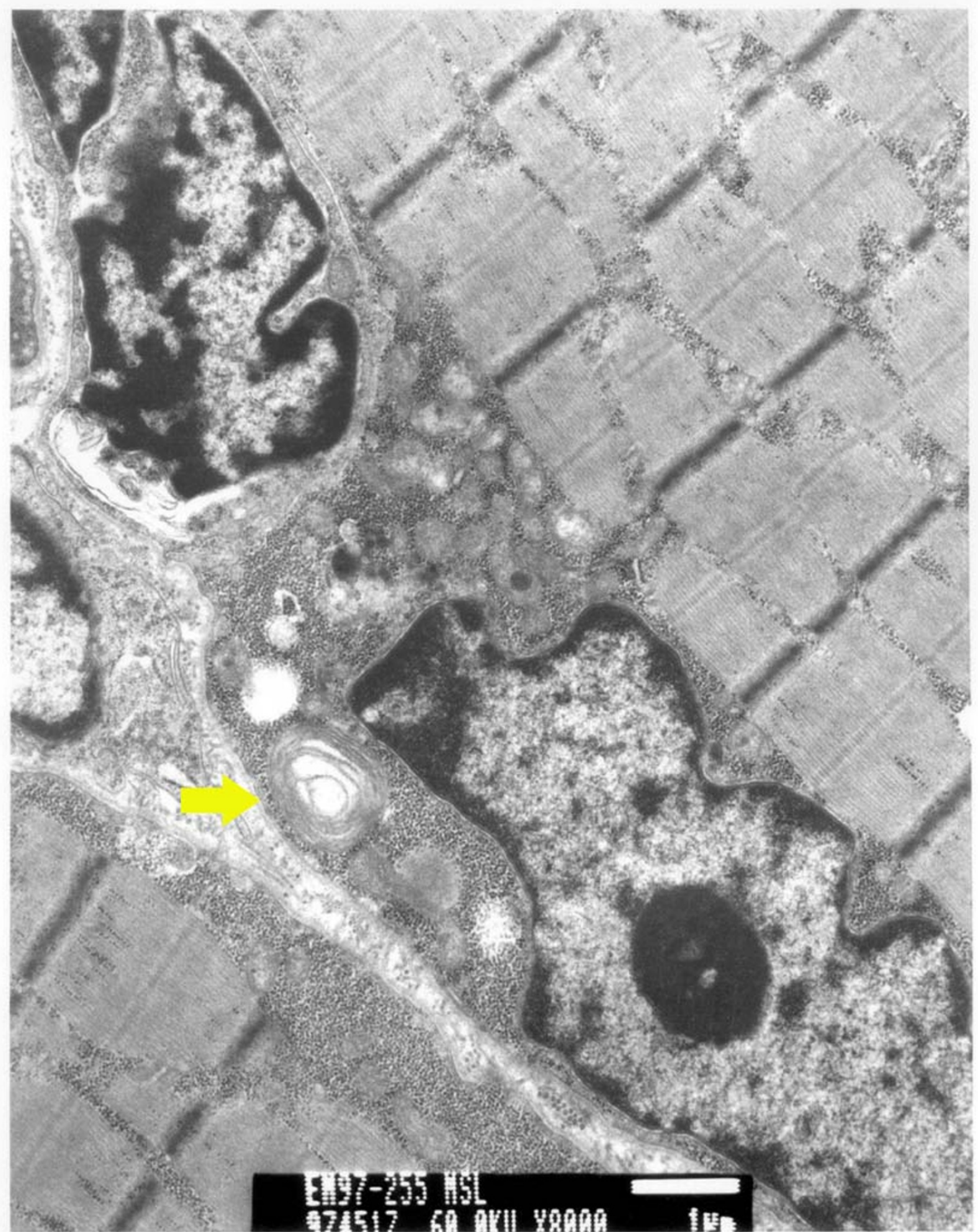

Figure 2

Electron microscopy of skeletal muscle. Abnormal concentric arrangements of cristae (arrow), with rare dense bodies can be seen. Notice excess glycogen and fat deposition which are features evocative of a mitochondrial myopathy. Focal Z-disc streaming can be seen. 
Table I: Respiratory chain analysis of patient's skeletal muscle tissue

\begin{tabular}{|c|c|c|c|}
\hline Enzyme & Complex & $\begin{array}{l}\text { Activity } \\
\left(\mu \mathrm{mol} / \mathrm{min}^{-1} / \mathrm{g}^{-1}\right)\end{array}$ & Normal reference mean \pm I SD \\
\hline Cytochrome c oxidase & IV & $2.56 *$ & $(2.8 \pm 0.52)$ \\
\hline Succinate cytochrome $\mathrm{c}$ reductase & II + III & 0.55 & $(0.7 \pm 0.23)$ \\
\hline NADH cytochrome c reductase & $I+I I I$ & 1.44 & $(1.02 \pm 0.38)$ \\
\hline NADH dehydrogenase & I & 29.32 & $(35.48 \pm 7.07)$ \\
\hline Citrate synthase & & $15.0 \mid$ & $(9.88 \pm 2.55)$ \\
\hline Succinate dehydrogenase & II & 1.15 & $(1 \pm 0.53)$ \\
\hline
\end{tabular}

$\mathrm{NADH}=$ reduced nicotinamide adenine dinucleotide $*$ Data represent the mean of 2 independent analyses on different muscle homogenates

Kearns-Sayre syndrome [17]. The complete AV block in Kearns-Sayre syndrome may also be associated less commonly with ventricular tachycardia, torsade de pointes and ventricular fibrillation as the ultimate and often fatal stage of the condition [18]. However, to our knowledge, ventricular tachycardia as a presenting feature has not been described in the context of mitochondrial cytopathies in the neonatal period.

\section{Causes of 3-MGC aciduria in children}

3-MGC aciduria is a rare hereditary organic aciduria characterized by increased urinary excretion of 3-MGC and 3MGR acids. At least 4 distinct clinical forms associated with 3-MGC aciduria have been described [19]. Type I 3MGC aciduria (Mendelian Inheritance in Man database *250950) due to 3-MGC CoA hydratase (EC 4.2.1.18) deficiency has a relatively benign clinical course including speech delay and macrochephaly; type II 3-MGC aciduria (Barth syndrome) (Mendelian Inheritance in Man database *302060) has a clinical picture that includes cardiomyopathy, recurrent infections, neutropenia, short stature and normal cognitive function and is caused by mutations in the tafazzin gene (G4.5) [20]; type III 3-MGC aciduria (Costeff optic atrophy syndrome) (Mendelian Inheritance in Man database *258501) was described in patients of Iraqi-Jewish origin with bilateral optic atrophy accompanied in some by movement disorders and caused by mutations in the OPA3 gene [21,22]; and type IV 3-MGC aciduria (Mendelian Inheritance in Man database *250951) presents with moderate to severe neurological disease, cardiac, ophthalmic, hepatic, and renal symptoms and it has been associated with mitochondrial disorders (Pearson syndrome, mitochondrial DNA depletion) or multiple respiratory chain defects [23-26]. This group does not have a defined primary biochemical or molecular defect. Our patient would fit in this latter clinically heterogeneous group although the degree of elevation of 3MGC seen in other cases could be as high as $600 \mathrm{mmol} /$ mol of creatinine. Barth syndrome, a cause of 3-MGC aciduria and cardiomyopathy, would be an unlikely diagnosis in our patient primarily due to absence of symptoms in female carriers secondary to presumed skewing of X-inactivation and lack of growth retardation and neutropenia. We suspect that her organic aciduria is associated with mitochondrial dysfunction. It has been speculated that an abnormality of translocation of 3-MGC acid across the mitochondrial membrane may be the source of 3-MGC aciduria in these patients [23]. The link between 3-MGC aciduria and mitochondrial dysfunction may involve failure of mitochondrial uptake of 3-MGC acid or potentially defective ubiquinone biosynthesis leading to increased levels of mevalonate in the mevalonate shunt pathway with subsequent increased synthesis of 3-MGC acid [27].

\section{MtDNA mutation analysis}

Although there is no direct proof of a respiratory chain (RC) defect in our patient, mitochondrial disorders cannot be ruled out, as normal RC activities have been occasionally reported in muscle samples from clinically affected patients with proven mtDNA mutations or mutations in nuclear genes that impact mitochondrial function [28-30]. Respiratory chain activity studies on endomyocardial biopsy would be helpful. Since no primary deleterious mtDNA mutation has been found in the proband and she was born to healthy parents with unremarkable family history, we hypothesize that the etiology of her mitochondrial dysfunction could reside in a still unidentified nuclear gene defect; although secondary mitochondrial dysfunction caused by an unknown inborn error of metabolism cannot be excluded completely. At the present time, the T3197C nucleotide substitution is considered a polymorphism and it is not thought to have pathogenic significance by itself [31]. Although most pathogenic mutations are heteroplasmic, many homoplasmic mutations have been reported to have synergistic effects in the presence of other primary mutations [32,33]. The only difference in mtDNA between the affected child and the asymptomatic mother is the A189G mutation in the hypervariable D-loop region. The A189G has been reported as a polymorphism in Mitomap database [34]. Whether this alteration would affect mtDNA replication or transcription is not known. A remarkable finding was 
the novel 568-573 insCCCCC, present in both mother and proband. This region contains a stretch of 6 cytosines (C's) in the wild type. The insertion of $5 \mathrm{C}^{\prime}$ s results in a long polyC tract. The polyC tract is located next to the mitochondrial transcription factor 1 (mtTF1) binding site and the major H-strand promoter sequence. It is not clear if the length of this poly $\mathrm{C}$ stretch would influence promoter activity or mtTF1 binding, thus, the transcription of mitochondrial RNA. Further investigations are necessary to define the clinical significance of the homoplasmic mtDNA alterations found in the proband and to know whether they may act as secondary mutations, synergistically with a primary defect (either nuclear or mitochondrial) that could affect the mitochondrial function and result in this clinical condition.

\section{Orotic aciduria and abnormal acylcarnitine profile as po- tential markers of mitochondrial disease}

It has been reported before that an increased excretion of orotate in sick children may not be uncommon and that a positive allopurinol load test may indicate unrecognized mitochondrial disease, making orotic acid as a potential marker of mitochondrial dysfunction [35]. A potential link between mitochondrial cytopathies and urea cycle dysfunction has also been suggested by the findings of hypocitrullinemia in patients with neurogenic weakness, ataxia and retinitis pigmentosa (NARP) syndrome (Mendelian Inheritance in Man database *551500) caused by a T8993G mutation in mtDNA that triggers ATPase deficiency [36,37]. It was hypothesized that the NARP mutation would cause complex $\mathrm{V}$ deficiency in the small intestine as well, thus reducing the availability of mitochondrial ATP required for citrulline synthesis. The presence of mild increase in the urinary excretion of orotic acid in this patient could also suggest mitochondrial dysfunction, convalidating this hypothesis.

It has been noticed that if a patient is suspected of having a mitochondrial disease, abnormal carnitine esters may help with the diagnosis, [38] and abnormal acylcarnitine profiles do not exclusively indicate fatty acid oxidation disorders [39]. Although the abnormal carnitine ester present in the proband is elevated in organic acidemias and is not usually present in mitochondrial cytopathies, we speculate that due to compromised ATP synthesis, secondary alterations may be generated in these patients by changes in mitochondrial protein synthesis, decrease in Krebs cycle intermediates and increased free radical formation, that could be responsible for a secondary impairment of mitochondrial biotin dependent carboxylases, but further elucidation is necessary before we could arrive to a conclusion in this regard.

\section{Conclusions}

Although alterations in mitochondrial morphology do not necessarily reflect well-defined mitochondrial disorders and we cannot completely exclude the possibility of an unknown metabolic disorder with secondary mitochondrial dysfunction, we speculate that all the clinical, biochemical and histological features in the proband can be attributed to disturbed mitochondrial energy metabolism. We suspect that this proband's 3-MGC aciduria reflects a defect in mitochondrial energy metabolism and that her mild orotic aciduria may be a nonspecific marker of mitochondrial dysfunction. Mitochondrial cytopathies are a group of disorders that are clinically heterogeneous with variable forms of presentation. We conclude that ventricular tachycardia in association with a Reye-like syndrome episode in the neonatal period may suggest mitochondrial dysfunction, and that the investigation of a mitochondrial cytopathy may be warranted in this clinical scenario. Our patient's neonatal presentation and relatively mild clinical course broadens the heterogeneous spectrum of clinical phenotypes associated with altered mitochondrial energy metabolism.

\section{List of abbreviations}

Mitochondrial DNA (MtDNA)

3-methylglutaconic (3-MGC)

3-methlyglutaric (3-MGA)

Polymerase chain reaction-allele specific oligonucleotide (PCR/ASO)

Temporal temperature gel electrophoresis (TTGE)

Cytosine (C)

Mitochondrial transcription factor 1 (MtTF1)

Neurogenic weakness, ataxia, and retinitis pigmentosa (NARP)

Respiratory chain (RC)

NADH: reduced nicotinamide adenine dinucleotide

\section{Competing interests}

None declared.

\section{Authors' contributions}

FS - provided long term subspecialty care of the patient, evaluated the patient and composed the manuscript.

AS - provided care during first admission and initial follow up, and made the primary diagnosis. 
JT - evaluated/managed the patient's cardiac arrhythmia and cardiomyopathy.

DA - performed and interpreted the specialized histochemical and electron microscopy studies on the muscle biopsy specimen.

LS - performed and interpreted the quantitative urine organic acid analysis.

L-JW - performed and interpreted the specialized mitochondrial DNA molecular studies.

\section{All authors read and approved the final manuscript.}

\section{Acknowledgements}

"Written consent was obtained from the patient or their relative for publication of the patient's details."

\section{References}

I. Holt IJ, Harding AE and Morgan HJA Deletions of muscle mitochondrial DNA in patients with mitochondrial myopathies. Nature 1988, 331:717-719

2. Wallace DC, Singh G, Lott MT, Hodge JA, Schurr TG, Lezza AM, Elsas LJD and Nikoskelainen EK Mitochondrial DNA mutation associated with Leber's hereditary optic neuropathy. Science 1988, 242: |427-| 430

3. Liang $\mathrm{M}-\mathrm{H}$ and Wong $\mathrm{L}-\mathrm{JC}$ Yield of mtDNA mutation analysis in 2000 patients. Am J Med Genet 1998, 77:395-400

4. Von Kleist-Retzow J-C, Cormier-Daire V, de Lonlay P, Parfait B, Chretien D, Rustin P, Feingold J, Rotig $A$ and Munnich $A$ A high rate (20-30\%) of parental consanguinity in cytochrome oxidase deficiency: Am J Human Genet 1998, 63:428-43

5. King TE and Howard RL Preparation and properties of NADH dehydrogenase from cardiac muscle. In: Methods in Enzymology: Oxidation and Phosphorylation (Edited by: Estabrook R, Pullman M) New York, Academic Press 1967, 275-294

6. King TE Preparation of succinate dehydrogenase and reconstitution of succinate oxidase. In: Methods in Enzymology: Oxidation and Phosphorylation (Edited by: Estabrook R, Pullman M) New York, Academic Press 1967, 322-331

7. Yonetan T Cytochrome oxidase: Beef heart. In: Methods in Enzymology: Oxidation and Phosphorylation (Edited by: Estabrook R, Pullman M) New York, Academic Press 1967, 332-335

8. Srere PA Citrate synthase. In: Methods in Enzymology: Oxidation and Phosphorylation (Edited by: Lowenstein J) New York, Academic Press 1969, 3-II

9. Wong L-JC and Bai R Real time quantitative PCR analysis of mitochondrial DNA in patients with mitochondrial disease. Am J Human Genet 2002, 7 I (suppl):S499

10. Glasgow JF and Middleton B Reye syndrome-insights on causation and diagnosis. Arch Dis Child 200 I, 85:35I-353

II. Treem WR Inherited and acquired syndromes of hyperammonemia and encephalopathy in children. Semin Liver Dis 1994, I 4:236-258

12. Hou J-W and Wang TR 3-methylglutaconic aciduria presenting as Reye syndrome in a Chinese boy. J Inherit Metab Dis 1995, I 8:645-646

13. Hou J-W, Chou S-P and Wang T-R Metabolic function and liver histopathology in Reye-like illness. Acta Paediatr 1996, 85: 10531057

14. Bonnet D, Martin D, de Lonlay P, Villain E, Jouvet P, Rabier D, Brivet $M$ and Saudubray J-M Arrhythmias and conduction defects as presenting symptoms of fatty acid oxidation disorders. Circulation 1999, 100:2248-2253

15. Pande SV Carnitine-acylcarnitine translocase deficiency. Am J Med Sci 1999, 3 1 8:22-27
16. Drachman DA Ophthalmoplegia plus: the neurodegenerative disorders associated with progressive external ophthalmoplegia. Arch Neurol 1968, I 8:654-674

17. Berenberg RA, Pellock JM, DiMauro S, Schotland DL, Bonilla E, Eastwood A, Hays A, Vicale T, Behrens M, Chutorian A and Rowland LP Lumping or splitting? 'Ophthalmoplegia-plus' or Kearns-Sayre syndrome? Ann Neurol 1977, I:37-54

18. Biard F, Philippe C, Berrut G, Lardy B and Slama R Kearns-Sayre syndrome:complete auriculovertebral block, torsade de pointes and ventricular fibrillation. Ann Cardiol Angeiol 1988, 37:529-534

19. Gibson KM, Elpeleg ON, Jakobs C, Costeff H and Kelly RI Multiple syndromes of 3-methylglutaconic aciduria. Pediatr Neurol 1993, 9:120-123

20. Bione S, D'Adamo P, Maestrini E, Gedeon AK, Bolhuis P-A and Toniolo $D$ A novel $X$-linked gene, $\mathbf{G 4 . 5}$ is responsible for Barth syndrome. Nat Genet 1996, I 2:385-389

21. Elpeleg ON, Costeff H, Joseph A, Shental I, Weitz R and Gibson KM 3-methylglutaconic aciduria in the Iraqi Jewish 'optic atrophy plus' (Costeff) syndrome. Dev Med Child Neurol 1994, 36: I67-I72

22. Anikster Y, Kleta R, Shaag A, Gahl WA and Elpeleg O Type III 3methylglutaconic aciduria (optic atrophy plus syndrome, or Costeff optic atrophy syndrome): identification of the OPA3 gene and its founder mutation in Iraqi Jews. Am J Hum Genet 2001, 69:1218-1224

23. Gibson KM, Bennett MJ, Mize CE, Jakobs C, Rotig A, Munnich A, Lichter-Konecki $U$ and Treftz FK 3-methylglutaconic aciduria associated with Pearson syndrome and respiratory chain defects. J Pediatr 1992, I 2 I:940-942

24. Scaglia F, Sutton VR, Bodamer OAF, Vogel H, Shapira SK, Naviaux RK and Vladutiu GD Mitochondrial DNA depletion associated with partial complex II and IV deficiencies and 3-methylglutaconic aciduria. J Child Neurol 2001, I 6: I 36-138

25. Ibel H, Endres W, Hadorn HB, Deufel T, Paetzke I, Duran M, Kennaway NG and Gibson KM Multiple respiratory chain abnormalities associated with hypertrophic cardiomyopathy and 3methylglutaconic aciduria. Eur J Pediatr 1993, 1 52:665-670

26. Figarella-Branger D, Pellissier JF, Scheiner C, Wernert F and Desnuelle $C$ Defects of the mitochondrial respiratory chain complexes in three pediatric cases with hypotonia and cardiac involvement. J Neurol Sci 1992, 108:105-I I3

27. Kelley RI and Kratz L 3-Methylglutaconic acidemia in SmithLemli-Opitz syndrome. Pediatr Res 1995, 37:67।-674

28. Corona P, Lamantea E, Greco M, Carrara F, Agostino A, Guidetti D, Dotti MT, Mariotti $C$ and Zeviani M Novel heteroplasmic mtDNA mutation in a family with heterogeneous clinical presentation. Ann Neurol 2002, 5 I: I I 8-122

29. Chinnery PF, Taylor DJ, Brown DT, Manners D, Styles P and Lodi R Very low levels of the mtDNA A3243G mutation is associated with mitochondrial dysfunction in vivo. Ann Neurol 2000, 47:38I-384

30. Hirano M, Silvestri G, Blake DM, Lombes A, Minetti C, Bonilla E, Hays AP, Lovelace RE, Butler I and Bertorini TE Mitochondrial neurogastrointestinal encephalomyopathy (MNGIE): clinical, biochemical, and genetic features of an autosomal recessive disorder. Neurology 1994, 44:721-727

31. Sternberg D, Danan C, Lombes A, Laforet P, Girodon E, Goossens M and Amselem $S$ Exhaustive scanning approach to screen all the mitochondrial tRNA genes for mutations and its application to the investigation of 35 independent patients with mitochondrial disorders. Human Molecular Genetics 1998, 7:33-42

32. Liang $M-H$ and Wong L-JC Novel nucleotide substitutions in mitochondrial DNA. J Inherit Metab Dis 1998, 21:87|-873

33. Shoffner JM and Wallace DC Oxidative phosphorylation diseases. In: The Metabolic and Molecular Bases of Inherited Disease (Edited by: Scriver CR, Beaudet AL, Sly WS, Valle D) New York, McGraw-Hill 1999, I535-1629

34. Mitomap Database

35. Bonham JR, Guthrie P, Downing M, Allen JC, Tanner MS, Sharrard M, Rittey C, Land JM, Fensom A, O'Neill D, Duley JA and Fairbanks LD The allopurinol load test lacks specificity for primary urea cycle defects but may indicate unrecognized mitochondrial disease. J Inherit Metab Dis 1999, 22: I74- I84

36. Parfait B, de Lonlay P, von Kleist-Retzow JC, Cormier-Daire V, Chretien D, Rotig A, Rabier D, Saudubray JM, Rustin P and Munnich A The neurogenic weakness, ataxia and retinitis pigmentosa 
(NARP) syndrome mtDNA mutation (T8993G) triggers muscle ATPase deficiency and hypocitrullinaemia. Eur J Pediatr 1999, 158:55-58

37. Rabier D, Diry C, Rotig A, Rustin P, Heron B, Bardet J, Parvy P, Ponsot G, Marsac C, Saudubray JM, Munnich A and Kamoun P Persistent hypocitrullinaemia as a marker for mtDNA NARP T 8993 G mutation? J Inherit Metab Dis 1998, 21:216-219

38. KG Sim, Carpenter K, Hammond J, Christodoulou J and Wilcken B Acylcarnitine profiles in fibroblasts from patients with respiratory chain defects can resemble those from patients with mitochondrial fatty acid beta-oxidation disorders. Metabolism 2002, $51: 366-37$ I

39. Scholte HR, Busch HF, Luyt-Houwen IE, Vaandrager-Verduin MH, Przyrembel $\mathrm{H}$ and Arts WF Defects in oxidative phosphorylation. Biochemical investigations in skeletal muscle and expression of the lesion in other cells. J Inherit Metab Dis 1987, I O(Suppl I):8I-97

\section{Pre-publication history}

The pre-publication history for this paper can be accessed here:

http://www.biomedcentral.com/1471-2431/2/12/prepub

Publish with Bio Med Central and every scientist can read your work free of charge

"BioMed Central will be the most significant development for disseminating the results of biomedical research in our lifetime. "

Sir Paul Nurse, Cancer Research UK

Your research papers will be:

- available free of charge to the entire biomedical community

- peer reviewed and published immediately upon acceptance

- cited in PubMed and archived on PubMed Central

- yours - you keep the copyright

Submit your manuscript here:

http://www.biomedcentral.com/info/publishing_adv.asp 